\title{
Interseccionalidade de Gênero, Classe e Raça e Vulnerabilidade de Adolescentes Negras às DST/aids'
}

\author{
Intersectionality of Gender, Class and Race, and \\ Vulnerability of Black Female Adolescents to STD/AIDS
}

\author{
Stella R. Taquette \\ Doutora em Medicina. Profa. Adjunta da Faculdade de Ciências \\ Médicas da Universidade do Estado do Rio de Janeiro. \\ Endereço: Av. Prof. Manoel de Abreu 444, 2 andar, Vila Isabel, CEP \\ 20550-170, Rio de Janeiro, RJ, Brasil. \\ E-mail: stella.taquetteðgmail.com \\ I Pesquisa financiada pelo Departamento de DST, Aids e Hepatites \\ Virais do Ministério da Saúde e UNESCO.
}

\section{Resumo}

Objetivo: verificar a vulnerabilidade ao HIV/aids de adolescentes femininas moradoras de favelas da cidade do Rio de Janeiro. Métodos: foi utilizada uma combinação de métodos, quantitativo e qualitativo. Na etapa quantitativa, realizou-se um estudo observacional de corte transversal por meio de entrevistas e exames clínico/laboratoriais para diagnóstico de DST, e, na qualitativa, desenvolveram-se grupos focais sobre os temas sexualidade, gênero e raça. Resultados: foram entrevistadas 816 adolescentes de 10 diferentes comunidades, com um grupo focal em cada favela: $74 \%$ eram negras, $39 \%$ eram sexualmente ativas e destas $24,4 \%$ eram portadoras de DST. Houve uma relação estatisticamente significativa entre a variável raça/cor negra e a atividade sexual. $\mathrm{Na}$ fase qualitativa, evidenciou-se que a discriminação racial sofrida é cotidiana e contribui para a construção de autoimagem negativa que aliada a pobreza, violência de gênero e dificuldade de acesso aos serviços de saúde ampliam a vulnerabilidade às DST/aids. Conclusão: o estudo sugere a criação de políticas que proporcionem o aumento da oferta de serviços de atendimento ginecológico a esse público, com ações que favoreçam a utilização de preservativo feminino e contribuam para reduzir a desigualdade social, de gênero e de raça.

Palavras-chave: DST/aids; Adolescência; Vulnerabilidade; Raça/Cor; Gênero; Violência. 


\section{Abstract}

Objective: To verify the vulnerability to HIV/AIDS of female adolescents that live in poor communities of the city of Rio de Janeiro. Methods: It was carried out with quantitative and qualitative analyses. The quantitative phase was a cross-sectional study, through interviews of 816 adolescents and clinical/ laboratory tests in ten different slums, and the qualitative phase was done on one focus group about sexuality of gender and race in each community. Results: $74 \%$ of the adolescents were black, 39\% had sexual activity and $24.4 \%$ of those had STD. A statistical significant association occurred between the black color/race and sexual activity. In the qualitative stage, it became evident that racial discrimination occurs every day and contribute to a negative self-concept. This, in addition to poverty, violence based in gender and bad access to health services, creates a vulnerability context to STD/ AIDS. Conclusion: This study suggests policies that offer more gynecologic services to this public, with actions that favor the use of feminine condom and contribute to the reduction of social, gender, and race inequality.

Keywords: STD/AIDS; Adolescence; Vulnerability; Race/Color; Gender; Violence.

\section{Introdução}

A epidemia da aids tem tido mudanças no seu perfil, com tendência à feminilização e pauperização. Na faixa etária de 13 a 19 anos houve inversão na razão de sexo dos casos de aids a partir de 1998, passando a acometer mais mulheres. Em 2005, esse indicador atingiu o valor de seis homens para cada 10 mulheres e a predominância de casos ocorre através de transmissão heterossexual. Quanto à raça/cor, a partir do ano 200o, quando essa categoria passou a ser informada, houve um aumento dos casos de aids na população negra, apesar de a análise dessa variável ser bastante limitada pela grande quantidade de casos notificados sem essa informação (Brasil, 2007). Quanto às DST, sua prevalência em adolescentes não é conhecida de forma precisa (Brasil, 2008). Os dados informados encontram-se bem abaixo das estimativas, pois somente a aids e a sífilis congênita são de notificação compulsória e muitos portadores de DST buscam tratamento em farmácias ou se automedicam. Soma-se a isso o fato de algumas DST serem assintomáticas, principalmente entre as mulheres (Codes e col., 2002; Jiménez e col., 2001).

No início da epidemia de aids, em que os principais acometidos eram homossexuais, usuários de drogas injetáveis, hemotransfundidos e prostitutas, utilizava-se o conceito de "grupo de risco" que posteriormente foi sendo substituído pelo de “comportamento de risco". Esses conceitos, entretanto, não traduzem o percurso epidemiológico da doença, pois houve uma diminuição acentuada da incidência de aids entre homossexuais masculinos e nos hemotransfundidos e está estabilizada no segmento de prostitutas e de usuários de drogas injetáveis. A epidemia, porém, avança entre as mulheres heterossexuais monogâmicas, que não pertencem a nenhum grupo de risco, nem tampouco têm comportamento sexual de risco. Ao contrário, encaixam-se no perfil mais tradicional e conservador do ponto de vista da moral sexual, oposto ao considerado "desviante" dos principais acometidos no início da epidemia. $\mathrm{O}$ que se verifica é que as vítimas atuais, em especial mulheres negras e pobres, vivem em contextos sociais em que vários fatores potencializam suas vulnerabilidades às DST/aids, entre eles a violência baseada em gênero, a discriminação racial, 
a pobreza e a baixa escolaridade. Ou seja, percebe-se que a epidemia é resultante não apenas da ação patogênica de um agente viral específico e sim de outros determinantes.

Constata-se também que as ações de saúde baseadas no conceito de grupo de risco para o controle da epidemia não foram suficientes, além de terem produzido estigma e preconceito em grande escala. Num segundo momento, abandonaram-se as estratégias preventivas de isolamento e abstinência dos grupos de risco e passou-se a focar o comportamento de risco, difundindo-se informações como o uso de preservativo, controle dos bancos de sangue e de material descartável entre os usuários de drogas injetáveis. Essas estratégias se mostraram superiores às primeiras, mas também não atingiram resultados satisfatórios, pois a epidemia rumou para grupos sociais enfraquecidos como os mais pobres, as mulheres, os negros e os jovens. Somando-se a isso, provocou tendência de culpabilização individual e a dedução de que a infecção é consequência da displicência pessoal (Ayres e col., 2003).

0 percurso da epidemia de aids tem mostrado que as chances de as pessoas adoecerem, ou seja, suas vulnerabilidades, são resultantes de um conjunto de aspectos, não apenas individuais, mas também coletivos e contextuais, que acarretam maior susceptibilidade à infecção e ao adoecimento. A percepção ampliada e reflexiva da epidemia revela que a vulnerabilidade é resultante do somatório de um conjunto de aspectos, individuais, sociais e coletivos, passando por comportamento, cultura, política e situação socioeconômica (Seffner, 2009; Ayres e col., 2003; Sánchez e Bertolozzi, 2007).

A mulher negra sofre comumente tríplice discriminação: ser mulher, negra e pobre. 0 racismo, a pobreza e o sexismo (conjunto de ações e ideias que privilegiam indivíduos de determinado gênero e orientação sexual e discriminam os que não têm esses atributos) são mais agudos nas mais jovens. As mulheres são as principais prejudicadas pelas políticas macroeconômicas neoliberais, pois têm poucas chances de competir no mercado de trabalho em virtude de passar boa parte do tempo ocupadas em serviços não remunerados e serem as principais cuidadoras da família (Giffin e Dantas-Berger, 2007). Os indicadores de saúde da população negra são reveladores das desigualdades raciais. Os coeficientes de mortalidade materna relacionados à raça/cor mostram que as negras sempre apresentam maior razão de mortalidade, sofrem duas vezes mais agressão física na gravidez e têm maior taxa de hipertensão arterial, diabetes, tabagismo e sífilis (Cavalcante e col., 2006; Lopes, 2005).

Em relação às adolescentes, destaca-se que são as vítimas preferenciais de abuso sexual e de exploração sexual comercial (ABRAPIA, 2008). Têm risco aumentado de infecções genitais, devido à maior exposição do epitélio uterino, e estão em posição de menor poder de negociação de práticas sexuais seguras, além de não terem reconhecida a legitimidade de seu exercício sexual (Taquette, 2009). Frequentemente lhes é negado atendimento nos serviços de saúde quando não acompanhadas de seus responsáveis, impedindo as ações de prevenção e tratamento de DST, essenciais para deter o avanço do HIV. A associação de pobreza/violência/sexo feminino e um maior risco de DST/aids foi verificada em estudos realizados com adolescentes e jovens (Taquette e col., 2003, 2004).

Apesar do quadro de vulnerabilidade desse segmento populacional, são escassas as pesquisas realizadas especificamente com esse público. Este estudo teve como objetivo identificar as diferenças étnico-raciais no processo de vulnerabilidade ao HIV/aids, em adolescentes femininas negras.

\section{Percurso Metodológico}

A população-alvo deste estudo foram adolescentes do sexo feminino, moradoras de 10 comunidades de favela da cidade do Rio de Janeiro. Os bairros onde se realizou o trabalho de campo compreenderam todas as áreas programáticas da cidade. Porém, por questões relacionadas à falta de segurança nas comunidades, estes não foram selecionados de forma aleatória e sim baseados na existência de vínculo anterior de trabalho desenvolvido pelo Núcleo de Estudos em Saúde do Adolescente da Universidade do Estado do Rio de Janeiro (Nesa-UERJ) em outros projetos.

Na etapa quantitativa da pesquisa, a amostra de 816 adolescentes estudada foi significativa, de acordo com o censo do IBGE de 200o. O método utilizado foi observacional, de corte transversal por meio 
de entrevista e exames clínico-laboratoriais para diagnóstico de DST. Seguiu-se um roteiro baseado na ficha informatizada "História do Adolescente" da OPAS-OMS (1995), que contemplava a avaliação de saúde da adolescente e a coleta de informações a respeito da vida social, autoclassificação racial, histórico de violência e inquérito detalhado sobre sexualidade. Foram feitos testes de confiabilidade e validade do instrumento, assim como das entrevistadoras. Todas as variáveis estudadas apresentaram valores de percentual de concordância acima de $90 \%$ da estatística kappa.

Após a entrevista, as adolescentes foram convidadas para uma consulta de enfermagem clínica e/ou ginecológica e coleta de sangue para exames sorológicos de pesquisa de DST/aids, conforme a abordagem sindrômica do Ministério da Saúde (Brasil, 2006) e as que tinham atividade sexual, para o exame colpocitológico preventivo e bacterioscópico/cultura da secreção vaginal. Houve, entretanto, limitações no diagnóstico das DST já que não foram realizados exames específicos para clamídias, devido ao seu alto custo, e do total de 299 entrevistadas que relataram já terem tido relações sexuais com penetração vaginal, somente 90 (30,1\%) se submeteram ao exame ginecológico. Na ocasião da entrevista, parte delas não se sentia preparada para esse exame, por estarem menstruadas ou por outros motivos. Resgatar essas adolescentes para realização do exame em outro momento foi uma tarefa árdua e muitas vezes inglória. Os dados quantitativos foram armazenados no software Access, transportados para o programa SPSS para análises de frequência, de associação de variáveis e testes de significância com valor de $\mathrm{p}<0,05$.

$\mathrm{Na}$ etapa qualitativa do estudo, realizou-se observação participante e um grupo focal para cada uma das dez comunidades, com no máximo 15 adolescentes, convidadas na ocasião da entrevista. A observação participante foi efetivada pela equipe de coordenação do estudo e registrada em diário de campo. O conteúdo das gravações das reuniões foi transcrito na íntegra, logo após a realização dos grupos. Todo o material coletado foi lido e relido exaustivamente para a organização dos relatos. Uma pré-análise identificou as principais variáveis temáticas e levantou hipóteses provisórias. Em seguida, estabeleceram-se interrogações para identificar conteúdo relevante e criar categorias específicas. Ao final, articularam-se os dados aos referenciais teóricos da pesquisa e identificaram-se algumas representações sociais cuja interpretação contou com a participação de equipe multidisciplinar no sentido de se obter uma visão de vários profissionais de formação diferenciada (Minayo, 2006a). Em síntese, para responder às questões suscitadas nesta pesquisa, chegando o mais próximo possível da realidade, foi utilizada uma triangulação de métodos com a combinação e o cruzamento de múltiplos pontos de vista e o emprego de variadas formas de coleta de dados (Minayo, 2006b).

Este projeto de pesquisa foi aprovado pelo Comitê de Ética em Pesquisa do Hospital Universitário Pedro Ernesto da Universidade do Estado do Rio de Janeiro. Todas as adolescentes que participaram assinaram o termo de consentimento livre e esclarecido, assim como seu responsável, quando presente, ou uma testemunha.

\section{Resultados e Discussão}

\section{Etapa quantitativa}

A faixa etária das entrevistadas variou entre 10 a 24 anos $(n=816)$, sendo que $96,6 \%$ eram menores de 20 anos. A maior parte era solteira (93,4\%) e $4,8 \%$ viviam em união estável. Em $2 \%$ dos casos a raça/cor não foi informada (n=16) e $74 \%$ do total se autodeclararam pardas ou pretas.

Em relação ao histórico familiar, 82,4\% das adolescentes conviviam com a mãe e a presença do pai for registrada por apenas $48,4 \%$ das famílias. As relações familiares foram percebidas como boas por $77,7 \%$ das entrevistadas. A relação boa com a mãe foi relatada por $82,5 \%$ das adolescentes e com o pai, mesmo ausente na maioria das famílias, foi referida positivamente por $60,8 \%$ delas. Esses dados confirmam as mães como os principais vínculos afetivos das adolescentes.

As moradias das adolescentes, apesar de localizadas em favelas, contavam com os insumos essenciais. Foi verificado que $98 \%$ das residências dispunham de energia elétrica, 96,7\% de água encanada, $92 \%$ de esgoto sanitário e 9o,4\% de coleta de lixo. Noventa e quatro por cento das casas eram de 
alvenaria e $29 \%$ dispunham de computador. 0 acesso à internet foi relatado por 22,8\% das entrevistadas. A TV foi um bem disponível em 96,1\% dos lares e o DVD em 72,5\%. As famílias de 52,4\% das adolescentes eram compostas de até 4 membros, $42,4 \%$ de 5 a 8 pessoas e $5,2 \%$ de nove ou mais.

Quanto à escolaridade, 92,8\% das adolescentes entrevistadas frequentavam a escola, sendo a repetência relatada por $41 \%$ delas. 0 principal motivo de não estar estudando, externado por 18,6\% das adolescentes, foi ter concluído os estudos e a gravidez apareceu em segundo lugar, informado por $16,9 \%$ delas. A defasagem escolar de dois ou mais anos entre a idade e o ano esperado foi observada em $28,6 \%$ das respondentes. Em relação aos hábitos, foi referido por $18,6 \%$ das adolescentes o consumo de bebidas alcoólicas em festas semanalmente; 9,8\% eram tabagistas e $2,3 \%$ consumiam drogas ilícitas como maconha, cocaína, crack ou solventes.

No histórico sobre violência, verificou-se que 15,1\% das adolescentes já tinham sido agredidas por membros de sua família e $6,5 \%$ por seus companheiros. Ter sofrido violência na escola foi relatado por $15,4 \%$ das adolescentes e 1,2\% nos serviços de saúde. As violências perpetradas por familiares e pelo companheiro compreenderam agressões físicas, sexuais, psicológicas e morais. Na escola, referiram brigas com colegas, xingamentos, racismos e agressões físicas. Quanto aos serviços de saúde, as queixas foram de discriminação racial, longa espera para serem atendidas, mau atendimento e ofensas verbais por parte dos funcionários.

No inquérito sobre puberdade e sexualidade, observou-se que aproximadamente $9 \%$ das adolescentes ainda não tinham menstruado. A menarca ocorreu aos 10 anos ou menos em $7 \%$ das meninas, entre 11 e 13 anos na maioria delas $(67,3 \%)$ e após os 13 anos em 16,1\%. Em relação à atividade sexual, 39\% afirmaram ter tido algum tipo de experiência sexual. Destas, o sexo vaginal foi praticado por 91,8\%, o sexo oral por $24,5 \%$ e o sexo anal por $10,7 \%$. A idade média da primeira relação sexual foi de 14,4 anos, dentre aquelas com idade informada.

Um percentual de 72,3\% das adolescentes com atividade sexual relatou ter tido de 1 a 2 parceiros sexuais no último ano e apenas $14,8 \%$ se relacionaram sexualmente com 3 a 4 parceiros no mesmo período. Esse baixo percentual contradiz a opinião do senso comum de que a adolescência é uma fase da vida que se caracteriza por uma variedade e multiplicidade de parcerias sexuais. Em estudo disponibilizado no Boletim Epidemiológico do Ministério da Saúde (Brasil, 2007), apenas 7\% dos adolescentes tiveram mais de cinco parceiros eventuais no último ano. Quanto à contracepção, 77,3\% das entrevistadas que praticaram sexo com penetração vaginal relataram usar algum método para evitar a gravidez. 0 mais utilizado foi o preservativo masculino por $61,5 \%$ das adolescentes. Somente 1,3\% delas usaram preservativo feminino. 0 contraceptivo de emergência já tinha sido utilizado por $12 \%$ das adolescentes. Das que usavam preservativo, 40,8\% o faziam sempre. Os motivos alegados para o não uso frequente de preservativo foram diversos, entre eles: ter parceiro fixo, não gostar, não se ver em risco, não ter acesso, alergia, o parceiro não gosta, uso de outro método contraceptivo, esquecimento, não ter disponível na hora, nunca conversou com o parceiro sobre isso e ter poucas relações sexuais. Vinte e sete por cento das adolescentes com atividade sexual já ficaram grávidas. Do total das que engravidaram, 40,7\% abortaram e, a maioria delas, de forma espontânea. Em relação ao histórico prévio de DST, apenas 7,8\% das sexualmente iniciadas relataram já ter tido.

O diagnóstico de DST foi realizado por um ou mais dos seguintes meios: exame clínico-ginecológico (na presença de lesões - vesículas, úlceras e condilomas, secreções purulentas, dor pélvica à mobilização do colo uterino), exame bacterioscópico da secreção vaginal (trichomonas e neisseria gonorrahae), exame colpocitológico e sorologias (HIV, hepatite B e C e sífilis). A incidência de DST neste grupo de adolescentes com experiência sexual que se submeteram ao exame ginecológico foi de $24,4 \%$. Devido ao fato de nem todas terem feito exames sorológicos e exames específicos da secreção vaginal para clamídia, podemos inferir que essa taxa, apesar de alta, pode estar subestimada. Considerando-se a DST principal, o diagnóstico mais frequente foi o de cervicite/doença inflamatória pélvica (DIP) em $45,4 \%$ das portadoras de DST, seguida do HPV (22,7\%), sífilis (18,2\%), e tricomoníase (13,6\%). Não houve nenhum caso de HIV, hepatite B ou C. Dentre os poucos dados disponíveis no Ministério da Saúde (Brasil, 2008) sobre a prevalência em populações es- 
pecíficas, o de sífilis na população de gestantes com mais de 13 anos é de $4 \%$, semelhante ao encontrado nesta pesquisa (4 casos em 90 exames). Apesar de não ter sido verificado nenhum caso de HIV positivo nesse grupo, vale ressaltar que ter uma DST aumenta as chances de infecção por esse vírus e os estudos evidenciam a incidência de quase cem por cento de HPV em mulheres HIV positivas (Levi e col., 2002).

Foram realizadas análises estatísticas com associações de variáveis categóricas por raça/cor (Teste de qui-quadrado de Pearson). Não foram encontradas diferenças significativas nas variáveis: convivência com o pai, defasagem escolar e uso de drogas por raça/cor. Sobre as experiências de violência, observou-se que as adolescentes negras informaram uma frequência três vezes maior de situações em que foram agentes de violência quando comparadas com as adolescentes não negras, sendo essa relação estatisticamente significativa (Tabela 1). Foi encontrada uma associação também significativa entre as variáveis raça/cor e atividade sexual (Tabela 2). Em relação ao histórico de DST, verificou-se uma associação com significância estatística entre ter tido uma DST e a raça negra (Tabela 3). Entretanto, o mesmo não foi verificado quanto ao diagnóstico de DST. Ressaltamos as limitações dessas análises devido ao número reduzido de exames ginecológicos realizados. Também não houve significância nas associações entre: idade da sexarca, histórico de gravidez e de abuso sexual por raça/cor.

\section{Tabela I - Distribuição percentual das adolescentes segundo violência por raça/cor autodeclarada}

\begin{tabular}{|c|c|c|c|c|c|c|c|c|}
\hline \multirow{2}{*}{ Variável } & \multicolumn{2}{|c|}{ Negra } & \multicolumn{2}{|c|}{ Não negra } & \multicolumn{2}{|c|}{ Total } & \multirow{2}{*}{$\chi^{2}$} & \multirow{2}{*}{$p$-valor } \\
\hline & $n$ & $\%$ & $n$ & $\%$ & $n$ & $\%$ & & \\
\hline Sofreu violência & & & & & & & 0,385 & 0,393 \\
\hline $\operatorname{sim}$ & 221 & 77,3 & 65 & 22,7 & 286 & 100,0 & & \\
\hline Não & 383 & 74,5 & 131 & 25,5 & 514 & 100,0 & & \\
\hline Total & 604 & 75,5 & 196 & 24,5 & 800 & 100,0 & & \\
\hline Agente de violência & & & & & & & 10,895 & 0,001 \\
\hline $\operatorname{sim}$ & 221 & 78,6 & 60 & 21,4 & 281 & 100,0 & & \\
\hline Não & 383 & 73,8 & 136 & 26,2 & 519 & 100,0 & & \\
\hline Total & 604 & 75,5 & 196 & 24,5 & 800 & 100,0 & & \\
\hline
\end{tabular}

Tabela 2 - Distribuição das adolescentes segundo experiência sexual por raça/cor autodeclarada

\begin{tabular}{|c|c|c|c|c|c|c|c|c|}
\hline \multirow{2}{*}{ Variável } & \multicolumn{2}{|c|}{ Negra } & \multicolumn{2}{|c|}{ Não negra } & \multicolumn{2}{|c|}{ Total } & \multirow{2}{*}{$\chi^{2}$} & \multirow{2}{*}{$p$-valor } \\
\hline & $\mathrm{N}$ & $\%$ & $n$ & $\%$ & $n$ & $\%$ & & \\
\hline Teve experiências sexuais? & & & & & & & 4,129 & 0,042 \\
\hline $\operatorname{sim}$ & 225 & 71,7 & 89 & 28,3 & 314 & 100,0 & & \\
\hline Não & 379 & 78,0 & 107 & 22,0 & 486 & 100,0 & & \\
\hline Total & 604 & 75,5 & 196 & 24,5 & 800 & 100,0 & & \\
\hline
\end{tabular}

Tabela 3 - Distribuição percentual das adolescentes segundo histórico de doenças sexualmente transmissíveis por raça/cor autodeclarada

\begin{tabular}{|c|c|c|c|c|c|c|c|c|}
\hline \multirow{2}{*}{ Variável } & \multicolumn{2}{|c|}{ Negra } & \multicolumn{2}{|c|}{ Não negra } & \multicolumn{2}{|c|}{ Total } & \multirow[b]{2}{*}{$\chi^{2}$} & \multirow{2}{*}{$p$-valor } \\
\hline & $n$ & $\%$ & $n$ & $\%$ & $n$ & $\%$ & & \\
\hline Histórico de DST & & & & & & & 7,109 & 0,004 \\
\hline $\operatorname{sim}$ & 17 & 100,0 & 0 & 0,0 & 17 & 100,0 & & \\
\hline Não & 208 & 70,0 & 89 & 30,0 & 297 & 100,0 & & \\
\hline Total & 225 & 71,7 & 89 & 28,3 & 314 & 100,0 & & \\
\hline
\end{tabular}




\section{Etapa qualitativa}

O número médio de participantes nos grupos foi de 11 adolescentes, e a mediana de tempo de duração das reuniões foi de 53 minutos. A análise partiu de três categorias gerais relacionadas a contextos de vulnerabilidade às DST/aids: Exercício Sexual na Adolescência, Desigualdade de Gênero e Discriminação Racial.

\section{Atividade Sexual de Adolescentes Femininas em Contextos de Pobreza}

O debate abordou os tipos de relacionamentos amorosos vivenciados pelos jovens na atualidade, como eles acontecem, que fatores estão envolvidos, as influências mais fortes e os motivos alegados para o uso de proteção em relação às DST e à gravidez. Foi discutido também o que representa o início da atividade sexual para a vida das meninas. Observaram-se dois tipos principais de relacionamentos amorosos, o "ficar" e o "namorar", cuja principal diferença entre eles é o compromisso assumido pelo casal e a fidelidade. Vários fatores intervêm na decisão de iniciar a atividade sexual, assim como as atitudes diante do risco de relações sexuais desprotegidas. Vejamos suas falas:

Ficar é dar um beijinho e depois largar.

Ficar é um hoje, outro amanhã.

Não é nada sério, só pra dizer que tem mais um na sua lista!

Eu namoro, euvou na casa do meu namorado, ele vai na minha casa.

Conhece a família, né?

Quando tá namorando rola sentimento, né?

0 risco de relações sexuais desprotegidas, segundo os relatos apreendidos, está associado à falta de conhecimento, de maturidade, de diálogo com a família. Muitas adolescentes referiram o desejo de melhorar de vida e de ter um companheiro, como motivo do início da vida sexual.

Acho que no caso, se for uma menina que tenha uma educação melhor, a menina vai tentar esperar.

Eu fiquei já grávida três vezes não por descuido meu, entendeu? Foi mais porque eu não tinha o apoio da minha família.
Eu quis perder minha virgindade porque eu quero virar independente, pô eu quero mostrar pro meu pai que eu não sou mais criança.

Hoje em dia as meninas estão engravidando só pra segurar o marido, né?

Já que ele tem dinheiro, eu não tenho, vou ficar com esse mesmo.

Sonha em ter um cheque, comprar o que quiser.

O desejo e a pressão social foram apontados como fatores de forte influência para o início da vida sexual. Pensar no futuro se apresentou como fator que contribui para a manutenção da virgindade. Abaixo podemos ver alguns exemplos:

Porque eu, eu tenho uma amiga que começou a vida sexual dela com 18 anos. Eu aplaudi ela de pé. Eu falei para ela: "cara, você é uma pessoa em extinção".

Os meninos, eles botam muita pressão, eu acho. Tem uma colega que o namorado dela falou assim pra ela: "vai ser uma prova de amor, se você realmente me ama, você vai ter que fazer isso".

A mídia influencia muito.

$\varepsilon$ você pode ver que toda a propaganda tem uma mulher sempre nua.

Tesão.

As pessoas falam: "ah, é bom".

É a curiosidade, poxa, todo mundo tem, aí elas acabam fazendo.

Quanto à vulnerabilidade às DST/aids, todas mostraram ter conhecimento do que é DST e aids, como se transmitem e como se previnem. Deram como sugestão para incentivar os adolescentes a usarem preservativo, mostrar cruamente o que são as doenças, os doentes de aids, como eles ficam mal. Ressaltaram que uma das dificuldades de se proteger é o fato de as pessoas que têm DST não aparentarem e dificilmente contarem que estão infectadas. Outra sugestão foi disponibilizar camisinhas em larga escala, nas comunidades e nas escolas e oferecer serviços de planejamento familiar em abundância. Sugeriram também que se inicie educação sexual para os adolescentes bem mais precocemente, a partir da sexto ano do ensino fundamental. Algumas 
não vão aos postos de saúde buscar camisinha para não ser alvo de comentários maldosos na comunidade. Os exemplos podem ser conferidos abaixo:

Eu acho que nas comunidades tinha que distribuir camisinha.

Têm muitos que não vão porque o colega vai zoar, aífica com vergonha de ir.

$\varepsilon$ porque no morro é tipo assim, se você engorda é que você tá grávida, se você emagrece, você tá doente.

Se amostrasse pra ver como é que fica o pessoal, já ia ter mais cuidado.

Porque falar que não tem muita informação é mentira.

Os relatos descritos sobre o exercício sexual das adolescentes demonstram que seu início tem ocorrido dentro de um contexto em que poucas são sujeitas de sua sexualidade e mais objeto de satisfação dos desejos dos outros. Há uma forte pressão social ao início da atividade sexual genital e uma cultura de erotização precoce em que o sexo é visto como objeto de consumo. Segundo alguns autores, os adolescentes têm relacionamentos muitas vezes até sem saber o nome de seus parceiros (Beckerman, 2005). Neste período de grande experimentação, muitas vezes os jovens abrem mão de seus desejos para seguir uma tendência do grupo. Eles querem deixar de ser crianças, têm muita curiosidade e sentem desejos sexuais intensos influenciados pelas mudanças hormonais pubertárias. E quando não há uma estrutura familiar protetora, mais precocemente eles aderem a modelos fora da família e se expõem a riscos. Em pesquisa sobre atividade sexual de adolescentes femininas, foi demonstrado que aquelas que são providas de investimento afetivo familiar se apropriam mais de sua sexualidade, agem com maior proteção e não se submetem meramente à satisfação dos desejos de outrem, ou seja, elas têm iniciação sexual em condições mais seguras e com menos risco (Taquette e col., 2008).

A alta frequência com que a participação dos pais foi citada pelas entrevistadas como um fator que influencia a atividade sexual de risco deixa clara a necessidade de incluir a família nas políticas públicas preventivas dos agravos da sexualidade precoce na adolescência. Esse dado é corroborado por outros estudos que preconizam a inclusão do familiar como protagonista do processo junto aos jovens nos programas de orientação sexual e promoção de saúde (Taquette e Vilhena, 2007).

\section{A Permanência das Desigualdades de Gênero}

A segunda categoria geral advinda das discussões nos grupos focais foi a "Desigualdade de Gênero". Verificou-se que os padrões hegemônicos de comportamento de gênero masculino e feminino se mantêm, com predominância do poder do homem sobre a mulher. A mulher é desvalorizada pela sociedade quando "perde" a virgindade e tem variados parceiros, enquanto o homem é prestigiado pelos mesmos motivos. Ela se submete com frequência a ter relações sexuais atendendo à vontade do parceiro. A reação diante da infidelidade também é representativa da permanência das desigualdades de gênero.

Os relatos revelaram que a mudança de status de virgem para não virgem tem representações variadas. Umas encaram como ganho, pois amadurecem, deixam de ser adolescentes, passam a ter experiência sexual; outras como perda, pois passam a ser olhadas com preconceito e por vezes são rejeitadas pela família; outra parcela destaca as transformações em sua vida resultantes do início da atividade sexual, como o dever com o cuidado da casa e ter de trabalhar. Vejamos alguns exemplos abaixo:

Acho que o corpo muda, a mentalidade também. Você se encara como uma mulher mesmo, não como uma criança. A partir do momento que você tem relação sexual, você não é mais considerada uma adolescente.

Fica se sentindo mais mulher, fica mais sensual, assim.

Pra eles, eles são garanhão, mas pra gente a gente já é como se diz, "piranha"!

Essa aí já é arrombada. Os seus pais pode te botar pra fora de casa. Por perder a virgindade acha que é a morte, acha que a vida acabou ali.

Muda totalmente o relacionamento com a família.

Você percebe que a família não tem mais confiança em você. 
"Ué, tu já não é mulher, vai caçar um serviço, vai arranjar uma casa, vai cuidar do teu marido, se sustentar comprar uma roupa".

Verificou-se que apesar de perceberem os riscos de uma relação sexual desprotegida, muitas são passivas no ato sexual e aceitam a dominação masculina. Algumas se apresentaram mais autônomas em relação à negociação do uso do preservativo, mas têm pouco controle sobre seu desejo. Vejamos alguns exemplos:

Se a mulher quer usar camisinha, então é melhor ela trocar de namorado e arrumar um namorado que gosta de usar camisinha, porque pra mim é assim.

Tem que ser assim, sem camisinha, sem sexo!

Ele insiste até ela falar: "ah, tá bom".

É muita lenha do menino.

A menina já ta lá naquele... fogo todo...

Se ela gostar dele, eu acho que ela faz. A maioria das vezes... estrupa.

A pessoa fica com medo de ser agredida, de ser estrupada.

Na opinião das adolescentes, todos os homens são infiéis e as mulheres também traem, mas por vingança, quando são traídas. Nas comunidades onde moram, há pouca privacidade, pois as casas são muito próximas umas das outras e há muita divulgação das intimidades das pessoas. As mulheres que traem são difamadas pela sociedade e pelas próprias mulheres. São chamadas de "piranha”, de "galinha”, etc. Ao contrário dos homens, que são elogiados por terem muitas parceiras. Eles são chamados de "garanhão" e muitas vezes referidos como motivo de orgulho de seus pais. Apesar de afirmarem que todos os homens são infiéis, as meninas quando estão namorando, confiam em seus parceiros e dispensam o uso do preservativo nas relações sexuais. A traição do homem é tratada pela sociedade como uma coisa natural e o homem traído é criticado e ridicularizado. Os relatos abaixo exemplificam as representações sociais observadas sobre a questão da infidelidade:

Mas eu fiz a mesma coisa que ele fez comigo.

A mulher trai por vingança!
A maioria dos homens, ele nunca é fiel.

A mulher corna é normal, o homem corno é chifrudo!

A gente é piranha, cachorra, safada, chamada de tudo quanto é nome.

Mulher é piranha e o homem é o garanhão,o gostoso!

Mas o homem já nasce com instinto animal. Ele trai, ele pode ficar com uma mulher num dia, noutro dia outra.

Se não fica com ninguém, já acha que ele éviado.

Verificou-se na observação participante e nos depoimentos nos grupos que o comportamento de gênero é aprendido desde a infância, dentro de casa. A menina, depois que deixa de ser virgem, perde muitos direitos dentro da família e passa a ser tratada com menos carinho porque "envergonhou" a família. No campo sexual, é obrigação da mulher transar sempre que seu parceiro quiser e ela muitas vezes negocia seu corpo para ser aceita e amada por ele e para conseguir objetivos materiais. Neste cenário é muito difícil negociar o uso do preservativo.

Os depoimentos citados exemplificam o caráter estruturante do gênero nas relações sociais. A mulher está em posição de menor poder que o homem e é vista como objeto de satisfação de seus desejos. Em geral, é submissa na relação sexual. 0 homem tem intensa intimidade com o prazer sexual e liberdade de seu exercício. Age como se não fosse possível controlar sua sexualidade. Por isso têm muitas parceiras e se arrisca. Os rapazes, apesar de apresentarem puberdade mais tardia, têm iniciação sexual mais precoce e com um maior número de parceiras. Já as moças apresentam histórico mais frequente de gravidez e de abuso sexual e menor uso de preservativo (Taquette e col., 2004).

\section{Discriminação Racial e Vulnerabilidade às DST/ aids}

A terceira categoria geral advinda das discussões em grupo foi a discriminação racial. Os relatos revelaram de forma contundente o cotidiano de discriminação e humilhação que as pessoas sofrem por serem negras. Isso tem como resultado baixa autoestima e vontade de clarear a família. Por isso, preferem se casar com homens brancos. Uma parte delas relacionou a raça negra à aids, por ser uma 
doença vinda da África. A maioria relatou não ter acesso fácil a serviços de saúde. Observou-se nas falas que elas se sentem discriminadas devido a questões relacionadas ao aspecto físico, ao caráter e à capacidade intelectual, como vemos nos exemplos a seguir:

Aquela miquinha, aquela macaca do cabelo duro!

Ou então você tá no ônibus e alguém levanta o braço, se você sentir um cheiro de suor, olham logo pra pessoa escura! "Ah, tu já saiu com ela, mas é feia pra caraca."

Na outra vez que a gente foi no zoológico, um monte de macaco, aí o pessoal falou: "preto, aí teus parentes."

Negro é muito feio.

Vai o segurança atrás de você

Branco no volante é doutor, preto no volante éladrão. Tem um ditado que é assim: "preto quando corre é bandido".

Viu um pretinho, já guarda a bolsa, esconde o dinheiro!

Se um preto entra no ônibus, vai assaltar o ônibus, aí esconde dinheiro!

Eles acha que nois... da cor assim, num tem a mesma capacidade dum branco.

Às vezes nós somos melhor do que eles, mas eles num dão oportunidade.

As manifestações de discriminação provocam grande sofrimento. Quando questionadas sobre casamento e filhos, ficou demonstrado o desejo que elas têm de deixarem de ser negras e assim não serem mais rejeitadas pela sociedade. Abaixo se verificam seus relatos:

Ah, eu gosto dum branquinho assim. O branco é pra clarear um pouco gente!

Porque, gente, isso é muito difícil, cabelo duro é uma tristeza.

Ah, eu nunca vou querer namorar com preto.

Minha mãe fala: "você tem que arrumar um namorado branquinho pra clarear a família!".

Verificou-se nas narrativas das adolescentes a associação entre a raça/cor negra e a feiura a falta de caráter, a incapacidade intelectual. Além disso, houve quem justificasse um maior risco de DST/aids pela atividade sexual mais intensa e precoce e ao fato de a aids ser uma doença advinda da África. Outro dado observado foi a dificuldade de acesso dessa população a serviços de saúde e também o atendimento de má qualidade. Vejamos seus relatos:

"Ih, a negrinha já tá grávida”. Tinha que ser preta.

Não adianta gente, todo mundo acha que é o perfil: preta, pobre, entendeu, só sabe ir pro pagode e rebolar, vai ficar grávida e não trabalhar.

Ah, eu acho que se você é preta você tem doença! As doenças sexualmente transmissivel já tá relacionado à pessoa negra. Principalmente a aids que dizem que veio da África...

... os negros têm mais facilidade pra pegar uma doença e já o branco não.

Pra você conseguir um atendimento tem que chegar de madrugada...

É só chegar uma preta que: "oh, já vem esses favelados". Tipo aquele doutor??? "Pô essa preta aí, essa negra, não vou atender ela não.

Mas, muito das vezes, os próprios médicos têm nojo de tocar num negro.

Na observação participante nas comunidades, verificou-se que as meninas se esforçam para alterar suas características raciais. Tentam alisar e alongar o cabelo e o pintam de loiro. Ser preta significa ser feia, suja, fedorenta, do cabelo ruim, "beiçuda”, ladra e incapaz. Para não sofrerem e serem aceitas, principalmente pelos homens, querem ser brancas. Muitas adolescentes passam a vida mordendo os lábios na intenção de reduzir seu tamanho, colocam pregador de roupa no nariz para afiná-lo e evitam comer feijão para não ficarem mais pretas.

\section{Considerações Finais}

O contexto em que vivem as adolescentes de comunidades pobres do Rio de Janeiro pode ampliar suas vulnerabilidades às DST/aids devido à intersecção de vários fatores, entre eles destacam-se a pobreza, a discriminação racial e a violência de gênero. 0 cotidiano de discriminação racial vivenciada por esse 
estrato populacional compromete o desenvolvimento e a autoestima e impede ou dificulta o acesso a bens e serviços. A pobreza em que sobrevivem acirra o racismo, o sexismo e a homofobia. Nesse sentido, o debate da conferência mundial contra o racismo realizada em Durbam em 2001 (Blackwell e Naber, 2002) destaca a importância do diálogo em torno da interseccionalidade, ou seja, das articulações entre a discriminação de gênero, a homofobia, o racismo e a exploração de classe, opressões comuns do contexto internacional da globalização (Carneiro, 2002).

Pode-se inferir que a origem das desvantagens e desigualdades em saúde desse grupo populacional se encontra na discriminação racial. Há uma inegável relação entre raça/cor e gênero na distribuição das riquezas. Apesar de poucos dados estatísticos sobre saúde de afrodescendentes estarem disponíveis, os que existem mostram que as mulheres negras estão nos mais baixos patamares de renda (Lopes, 2005). Elas apresentam menor escolaridade, piores condições de moradia e, ao mesmo tempo, usam menos métodos contraceptivos, têm mais filhos e vivem mais sozinhas, sem companheiro. Esses dados levam a crer que embora na sociedade brasileira não exista uma segregação racial legal, o significado social negativo atribuído a determinados padrões fenotípicos resulta em tratamento desigual e em enorme barreira que impede e dificulta a mobilidade social da população negra.

A discriminação racial evidenciada nas narrativas das adolescentes pesquisadas mostra que mulheres e homens, brancos e negros ocupam lugares diferentes nas redes sociais e trazem experiências distintas de viver e adoecer. Esses dados devem ser levados em consideração na elaboração de políticas públicas, para que ofereçam tratamento diferente àqueles que estão inseridos de forma desigual na sociedade, contemplando de fato suas necessidades e promovendo o direito à igualdade. Segundo Ayres e colaboradores (2003), são ações indissociáveis na prática preventiva e do cuidado a intervenção estrutural, a organização comunitária, a construção da cidadania, o ativismo político, a ação jurídica e os direitos humanos. Sugere-se em curto prazo investimentos no aumento da oferta de serviços de atendimento ginecológico a esse público, em médio prazo ações que favoreçam a utilização de preservativo feminino e em longo prazo políticas de ação afirmativa para reduzir a desigualdade social, de gênero e de raça.

\section{Agradecimentos}

Agradeço o empenho de toda a equipe de pesquisa: Maria Helena Ruzany, Zilah Meirelles, Clátia Regina Vieira, Regina Célia de Melo, Ana Isabel Coelho Dias da Silva, Danielle Cristina Pereira, Mônica Silva de Jesus, Ana Beatriz Carvalho Britto dos Santos, Marinalda de Souza Soares, Lidiane Peixoto de Almeida, Ana Maria Menezes de Sousa, Adriana Oliveira Rodrigues e Cristielle Alves da Silva e dos laboratórios parceiros (Diagnósticos da América, Laboratório de Virologia da Fiocruz e de Microbiologia do Hospital Universitário Pedro Ernesto) no desenvolvimento do estudo.

\section{Referências}

ABRAPIA (Associação Brasileira Multiprofissional de Proteção à Infância e à Adolescência). Abuso sexual de crianças e adolescentes. Disponível em: http://www.observatoriodainfancia.com.br . Acesso em o8 de mar. 2008.

AYRES, J. R. C. M. et al. O Conceito de Vulnerabilidade e as Práticas de Saúde: novas perspectivas e desafios. In: CZERESNIA, D. (Org.). Promoção da saúde: conceitos, reflexões, tendência. Rio de Janeiro: Fiocruz, 2003, p.117-139.

BECKERMAN, M. Geração T.E.E.N.: Transei e Esqueci o Nome. Rio de Janeiro: Ediouro, 2005.

BLACKWELL, M.; NABER, N. Interseccionalidade em uma era de globalização: as implicações da conferência mundial contra o racismo para práticas feministas transnacionais. Revista Estudos Feministas, Florianópolis, v. 10, n. 1, p. 189-198, jan. 2002.

BRASIL. Ministério da Saúde. Manual de Controle das Doenças Sexualmente Transmissíveis DST. Brasília: Editora Ministério da Saúde; 2006.

BRASIL. Ministério da Saúde. Boletim epidemiológico Aids/DST. Ano IV n. o1. Brasília: Editora Ministério da Saúde, jan./jun. 2007. Disponível em: < http://www.portalsida.org/ Article_Details.aspx?ID=7764>. Acesso em: 28 mar. 2008. 
BRASIL. Ministério da Saúde. Prevalências de DST em populações específicas. Disponível em: <http://www2.aids.gov.br/services/

DocumentManagement/FileDownload.EZTSvc. asp? DocumentID $=\left\{91 \mathrm{D}_{31} \mathrm{C}_{2} \mathrm{~A}-3639-45 \mathrm{~B} 7-9 \mathrm{E}_{2} 6-\mathrm{EAF}_{3}\right.$ 56142FC9\}\&ServiceInstUID $=\{$ B8EF5DAF-23AE-4891AD 36-1903553A3174\}>. Acesso em: 28 de mar. 2008.

CARNEIRO, S. A. A Batalha de Durban. Revista Estudos Feministas, Florianópolis, v. 10, n. 1, p. 209-214, jan. 2002.

CAVALCANTI, L. F.; GOMES, R.; MINAYO, M. C. S. Representações Sociais de profissionais de saúde sobre violência sexual contra a mulher: estudo em três maternidades do Rio de Janeiro. Cadernos de Saúde Publica, Rio de Janeiro, v. 22, n. 1, p. 31-39, jan. 2006.

\section{CENTRO LATINOAMERICANO DE}

PARINATOLOGIA Y DESARROLLO HUMANO.

CLAP (OPS/OMS). Montevideo, Uruguay.

Publicación Científica CLAP 1342.01, agosto 1995.

CODES, J. S. et al. Detecção de Doenças

Sexualmente Transmissíveis em Clínica de Planejamento Familiar da Rede Pública no Brasil. Revista Brasileira de Ginecologia e Obstetrícia, Rio de Janeiro, v. 24, n. 2, p.101-6, mar. 2002.

GIFFIN, K.; DANTAS-BERGER, S. M. Violência de gênero e sociedade de risco: uma abordagem relacional. In: TAQUETTE, S. R. (Org.). Violência contra a mulher adolescente/jovem. Rio de Janeiro: EDUERJ, 2007, p. 55-60.

JIMÉNEZ, A. L. et al. Prevenção de doenças sexualmente transmissíveis em mulheres: associação com variáveis sócio-econômicas e demográficas. Cadernos de Saúde Pública, Rio de Janeiro, v. 17, n. 1, p. 55-62, jan./fev. 2001.

LEVI, J. E. et al. High Prevalence of Human Papillomavirus (HPV) Infections and High Frequency of Multiple Genotypes in Human Immunodeficiency Virus Infected Women in Brazil. Journal of Clinical Microbiology, Washington, v. 40, n. 9, p. 3341-3345, sept. 2002.

LOPES, F. Para além das barreiras dos números: desigualdades raciais e saúde. Cadernos de Saúde Pública, Rio de Janeiro, v. 21, n. 5, p. 1595-16o1, set./out. 2005.
MINAYO, M. C. S. O Desafio do conhecimento: pesquisa qualitativa em saúde. São Paulo: Hucitec; Rio de Janeiro: Abrasco, 2006.

MINAYO, M. C. S. Introdução. Conceito de avaliação por triangulação de métodos. In: MINAYO, M. C. S.; ASSIS, S. G.; e SOUZA, E. R. (Org.). Avaliação por triangulação de métodos: abordagem de Programas Sociais. Rio de Janeiro: Fiocruz; 2006. p. 19-51.

SÁNCHEZ, A. M.; BERTOLOZZI, M. R. Pode o conceito de vulnerabilidade apoiar a construção do conhecimento em Saúde Coletiva? Ciência \& Saúde Coletiva, Rio de Janeiro, v. 12, n. 2, p. 319324, mar./abr. 2007.

SEFFNER, F. O conceito de vulnerabilidade: uma ferramenta útil em seu consultório. In: BRASIL. Ministério da Saúde. Departamento de DST, Aids e Hepatites Virais. Disponível em: <http://www.aids. gov.br/sites/default/files/vulnerabilidade.rtf>. Acesso em 17 jul. 2009.

TAQUETTE, S. R.; VILHENA M. M.; PAULA, M. C. Doenças sexualmente transmissíveis e gênero: um estudo transversal com adolescentes no Rio de Janeiro. Cadernos de Saúde Pública, Rio de Janeiro, v. 20, n. 1, p. 282-29o, jan./fev. 2004.

TAQUETTE, S. R. O paradoxo da moral sexual na adolescência e as DST/aids. In: Aids e juventude: gênero, classe e raça. Rio de Janeiro, EDUERJ, 2009. p. 135-154.

TAQUETTE, S. R. et al. Relacionamento violento na adolescência e risco de DST/aids. Cadernos de Saúde Pública, Rio de Janeiro, v. 19, n. 5, p. 14371444, set./out. 2003.

TAQUETTE, S. R.; VILHENA, M. M. Sexualidade na Adolescência na Contemporaneidade. In: TAQUETTE, S. R. (Org.). Violência contra a mulher adolescentel jovem. Rio de Janeiro: EDUERJ, 2007. p. 107-114.

TAQUETTE, S. R.; VILHENA, M. M. Uma contribuição ao entendimento da iniciação sexual feminina na adolescência. Psicologia em Estudo, v. 13, n. 1, p. 105-114, jan./mar. 2008.

Recebido em: 07/10/2009 Reapresentado em: 07/04/2010 Aprovado em: 04/05/2010 